\title{
Familial Glucocorticoid Deficiency Type 1 due to a Novel Compound Heterozygous MC2R Mutation
}

\author{
Artur Mazur $^{\mathrm{a}}$ Katrin Koehler $^{\mathrm{b}} \quad$ Markus Schuelke $^{\mathrm{c}}$ Mandy Skunde $^{\mathrm{b}} \quad$ Mariusz Ostański $^{\mathrm{a}}$ \\ Angela Huebner ${ }^{b}$ \\ a Institute of Physiotherapy, University of Rzeszów, Poland; ${ }^{b}$ Children's Hospital, Technical University of Dresden, \\ Dresden, and 'Department of Neuropediatrics, Charité University Medical Center, Berlin, Germany
}

\section{Established Facts}

- Familial glucocorticoid deficiency (FGD) is a rare, genetically heterogeneous, autosomal-recessive disease characterized by ACTH-resistant adrenal failure.

- About $25 \%$ of the patients carry mutations in the melanocortin 2 receptor gene (MC2R, FGD type 1) and $20 \%$ mutations in the melanocortin 2 receptor accessory protein gene (MRAP, FGD type 2), whereas more than $50 \%$ of the patients lack mutations in both genes.

\section{Novel Insights}

- Prolonged jaundice, constipation, profound skin hyperpigmentation and muscular hypotonia can be the first signs of the disease.

- The novel p.Leu46fs mutation is the first frameshift mutation within the first transmembrane domain of the melanocortin 2 receptor (MC2R).

- The novel p.Val49Met mutation is at the junction of the first transmembrane domain to the first intracellular loop. The affected amino acid valine 49 is highly conserved between different species and molecular modeling revealed that the substitution of valine 49 by methionine results in the recruitment of 48Ala and 49Met into the alpha helix of the first transmembrane domain (TMD) of the ACTH receptor which consecutively enables an interaction between 49Met and 273Pro (TMD VII).

\section{Key Words}

Familial glucocorticoid deficiency $\cdot$ Isolated glucocorticoid deficiency $\cdot$ Hereditary unresponsiveness to ACTH $\cdot$ MC2R

\section{Abstract}

Objective: Description of the clinical, biochemical and genetic features of a Polish patient with familial glucocorticoid deficiency. Methods: Detailed clinical investigation, hormonal analysis and sequencing of the coding region of the melanocortin 2 receptor (MC2R) gene in this patient. Results: We report on a 3-month-old boy with familial glucocorticoid deficiency who presented at the age of 3 months with skin hyperpigmentation, muscle weakness, mild jaundice and constipation. Hormonal analyses revealed high ACTH and TSH serum concentrations, low serum cortisol concentration along with normal blood electrolytes. On hydrocortisone supplementation, the disease symptoms disappeared and the child recovered completely. His physical and mental development progresses normally. Genetic anal-

\section{KARGER}

Fax +4161306 1234 E-Mail karger@karger.ch www.karger.com (c) 2008 S. Karger AG, Basel

0301-0163/08/0696-0363\$24.50/0

Accessible online at:

www.karger.com/hre
Artur Mazur, MD

Institute of Physiotherapy

University of Rzeszów, ul.Warszawska 26a

PL-35205 Rzeszów (Poland)

Tel. +48 178664 244, Fax +48 178664 145, E-Mail drmazur@poczta.onet.pl 
ysis disclosed a novel compound heterozygous MC2R mutation p.Leu46fs and p.Val49Met. Conclusion: The heterozygous p.Leu46fs mutation adds to the small number of $M C 2 R$ nonsense mutations and is the first frameshift mutation within the first transmembrane domain of the receptor. According to molecular modeling the Val49Met mutation results in a structural change of the first transmembrane domain and in a potential novel interaction of the transmembrane domains I and VII. C Copyright $\odot 2008$ S. Karger AG, Basel

\section{Introduction}

Familial glucocorticoid deficiency (FGD) is a rare autosomal-recessive disorder, which was first described by Shepard et al. [1] in 1959. The disorder belongs to a group of diseases associated with ACTH-resistant adrenal failure. FGD is synonymously named isolated glucocorticoid deficiency or hereditary unresponsiveness to ACTH. FGD is genetically heterogeneous in that only $25 \%$ of the patients carry mutations in the melanocortin 2 receptor (ACTH receptor) gene (MC2R) [2-6]. These patients were classified as having FGD type 1. It has recently been shown that $20 \%$ of all FGD cases bear mutations in the gene for melanocortin 2 receptor accessory protein $(M R A P)$ [7]. FGD type 1 and type 2 patients show no significant phenotypic differences $[6,7]$. More than $50 \%$ of the patients lack mutations in both genes, $M C 2 R$ and $M R A P$ [5], and at least one fur ther gene locus on chromosome 8q12.1-q21.2 has been identified [8]. Here we report on a patient with FGD due to a novel compound heterozygous $M C 2 R$ mutation.

\section{Case Report}

A male infant, born at 38 weeks of gestation [birth weight $3,850 \mathrm{~g}$ (50th percentile), length $54 \mathrm{~cm}$ (90th percentile)] was admitted to the hospital at the age of 3 months because of prolonged jaundice (total bilirubin level $20.7 \mathrm{mmol} / \mathrm{l}$, normal range (NR) 1.7-20.7 $\mathrm{mmol} / \mathrm{l}$ ) and constipation. On admission, the child presented with profound skin hyperpigmentation and muscular hypotonia the latter being present since the postnatal period. Liver enzyme levels (alanine aminotransferase, aspartate aminotransferase, gamma-glutamyl-transpeptidase) remained within normal ranges. Ultrasound of liver and biliary ducts did not show any pathology. Blood cell count, hemoglobin concentration and erythrocyte osmotic resistance were normal. Thyrotropin (TSH) level was elevated with $13.9 \mathrm{mU} / \mathrm{l}$ (NR 0.62-8.05 mU/l), whereas thyroid hormones were within reference values. Although the bilirubin level normalized and constipation disappeared after 10 days of hospitalization, muscle weakness and skin hyperpigmen- tation persisted. At cerebral ultrasound examination and magnetic resonance (MR) scans of the brain no structural abnormalities were found to be responsible for the observed muscular hypotonia. Hormonal analysis revealed low levels of cortisol throughout the day (8 a.m. $10.9 \mathrm{nmol} / \mathrm{l}, 2$ p.m. $17.2 \mathrm{nmol} / \mathrm{l}$ and 10 p.m. $11.4 \mathrm{nmol} / \mathrm{l}$; NR morning cortisol 165.5-786.3 nmol/l, NR afternoon cortisol $110.3-413.8 \mathrm{nmol} / \mathrm{l})$. ACTH level was $>1,275$ $\mathrm{pmol} / \mathrm{l}(\mathrm{NR}<10 \mathrm{pmol} / \mathrm{l})$. A high prolactin (PRL) level of $20 \mu \mathrm{g} / \mathrm{l}$ (NR 3.9-20.1 $\mu \mathrm{g} / \mathrm{l}$ ) was found, while serum 17-hydroxyprogesterone and plasma renin concentrations were within the normal ranges. A 24-hour urine steroid excretion examination was performed twice and revealed a complete lack of cortisol excretion with normal excretion of mineralocorticoids and androgens. At abdominal ultrasound, the adrenal glands appeared hypoplastic. During the time of hospitalization, no water-electrolyte disturbances or hypoglycemic episodes were observed. ACTH levels in the parents of the index patient were within normal ranges. In the clinically healthy 6-year-old sister the ACTH level was slightly elevated (13.9 pmol/1, NR $<10 \mathrm{pmol} / \mathrm{l})$, whereas the 24-hour urine steroid profile was normal.

With gas chromatography mass spectrometry (GCMS), we revealed normal organic and amino acid levels excluding organoacidopathies and disturbances in amino acid metabolism. Normal values of very-long-chain fatty acids (VLCFA) excluded adrenoleukodystrophy as a cause for the adrenal failure of the child. The patient showed a normal male 46,XY karyotype. Initially, the patient was commenced on $30 \mathrm{mg} / \mathrm{m}^{2} /$ day hydrocortisone and subsequently, on a maintenance dose of $15-20 \mathrm{mg} / \mathrm{m}^{2} /$ day. On treatment, the general state of the child improved quickly, muscle tonus normalized, and skin hyperpigmentation gradually disappeared. Throughout the observation period (18 months) his body weight and height remained within the normal values for age and parents height (father $186 \mathrm{~cm}$, mother $168 \mathrm{~cm}$ ). At the chronological age of 21 months his bone age was differentially delayed by between 3 months (carpal bones) and 18 months (metacarpals and finger bones). After 4 months of hydrocortisone treatment the ACTH level gradually decreased to $18.7 \mathrm{pmol} / \mathrm{l}$. At regular follow-up investigations electrolytes, glucose concentration, and arterial blood pressure remained normal. Under L-thyroxine substitution TSH levels normalized within 1 week and remained normal during the time of therapy. After 3 months L-thyroxine treatment was stopped, and during a 1.5-year follow-up period TSH and free thyroxine (fT4) levels remained within normal ranges.

\section{Molecular Genetic Results}

Mutation analysis of the $D A X 1$ gene revealed no abnormality thus excluding congenital adrenal hypoplasia. Based on the clinical picture and hormonal levels, the diagnosis of FGD was proposed. Sequencing analysis of the $M C 2 R$ gene revealed a compound heterozygous mutation combining two novel mutations: a G $>$ A transition c. $145 \mathrm{G}>\mathrm{A}$ resulting in a missense mutation (p.Val49Met) on one allele and a single nucleic acid deletion (c.137delT) resulting in a frameshift after Leucin 46 (p.Leu46fs). As 
Fig. 1. $M C 2 R$ mutations in the index patient with FGD and his family. Sequence chromatograms of the patient, his healthy parents and sister in comparison with the respective wild-type (control) sequence. Only in sequence chromatograms of the reverse reaction is the $\mathrm{G}>\mathrm{A}$ mutation visible in the patient due to the adjacent frameshift mutation. The arrow indicates the nucleotide altered by the mutation that occurred at c.137delT and c.145G $>$ A. The nomenclature is in accordance to den Dunnen (http://www.hgvs.org/mutnomen/).

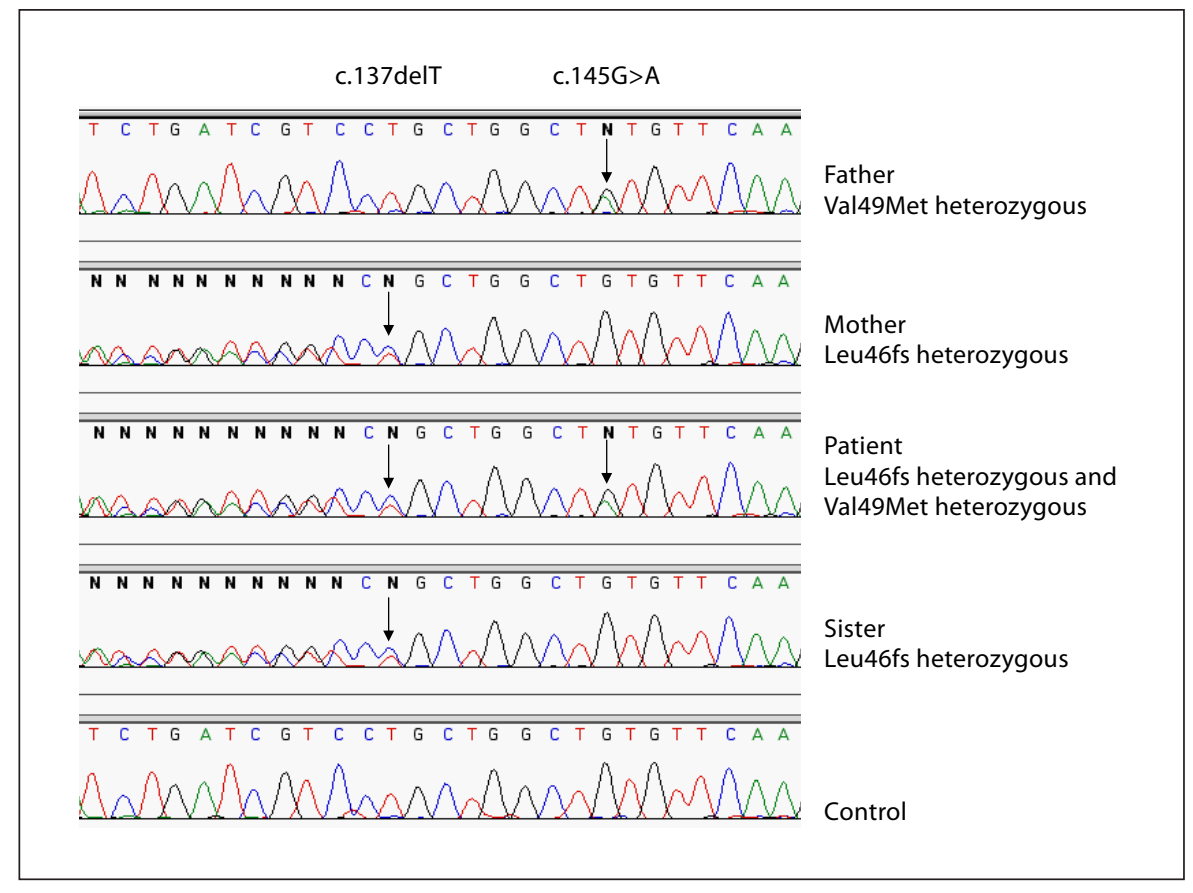

expected, the parents are heterozygous carriers of the disease in that the father harbors the heterozygous p.Val39Met mutation, and the mother and healthy sister of the patients carry the heterozygous c.137delT deletion (fig. 1). The p.Leu46fs and p.Val49M mutations have not been found in 60 unrelated healthy control subjects.

\section{Molecular Modeling of the Val49Met Mutation}

The MC2 receptor belongs to the G-protein coupled receptors (GPCR). This large group of proteins share seven transmembrane domains (TMD) as their common structural denominator. As only a 3D structure exists for bovine rhodopsin (PDB: 1HZX), other GPCRs can be modeled according to a rule-based technique [9] taking into account multiple sequence alignments of a certain subfamily of receptors, and the clear determination of the trans-membrane regions. As no experimental evidence exists for the structure of the loops that connect the helices, no inference can be made about these. The position of the TMDs of the MC2R was taken from the GPCR-database (GPCRDB, http://www.gpcr.org/7tm). The TMDs are depicted in a 2D snake diagram (fig. 2a) [10]. The 3D structure of the seven TMDs was modeled with the publicly available GPCR software in (SWISS-MODEL, http:// swissmodel.expasy.org) and the graphic output was generated with SWISS DeepView v3.7 and rendered with the public domain software POVRAY. The mutated 49Val at the C-terminus of the first TMD is not part of the alphahelix which ends at 47Leu. In the presence of the Val49Met mutation, both 48Ala and 49Met are recruited into the alpha-helix of TMD I (fig. 2d, e), possibly distorting the original structure. Additionally the methyl-groups of 49Met and 273Pro (TMD VII) may come into close proximity (5.1 ̊̊) thus enabling hydrophobic interaction between them. Potential interactions of $49 \mathrm{Met}$ with the first intracellular loop (AA48-58) cannot be inferred. In contrast, the alpha-helix of TMD I is not changed with the known Val45Ile polymorphism (fig. 2f, g).

\section{Discussion}

Patients with FGD usually present with an isolated glucocorticoid production defect. Very high ACTH levels in the presence of low cortisol levels indicate a defect of ACTH signaling either at the ACTH receptor level or in the signal transduction system.

Many cases of FGD type 1 have been associated with mutations in the $M C 2 R$ gene, and these mutations have been shown to segregate with the disease in affected families [5]. In our index patient we identified two novel heterozygous mutations in the melanocortin 2 receptor which lie within the first transmembrane domain (TMD I) and at the junction of the TMD I to the first intracel- 


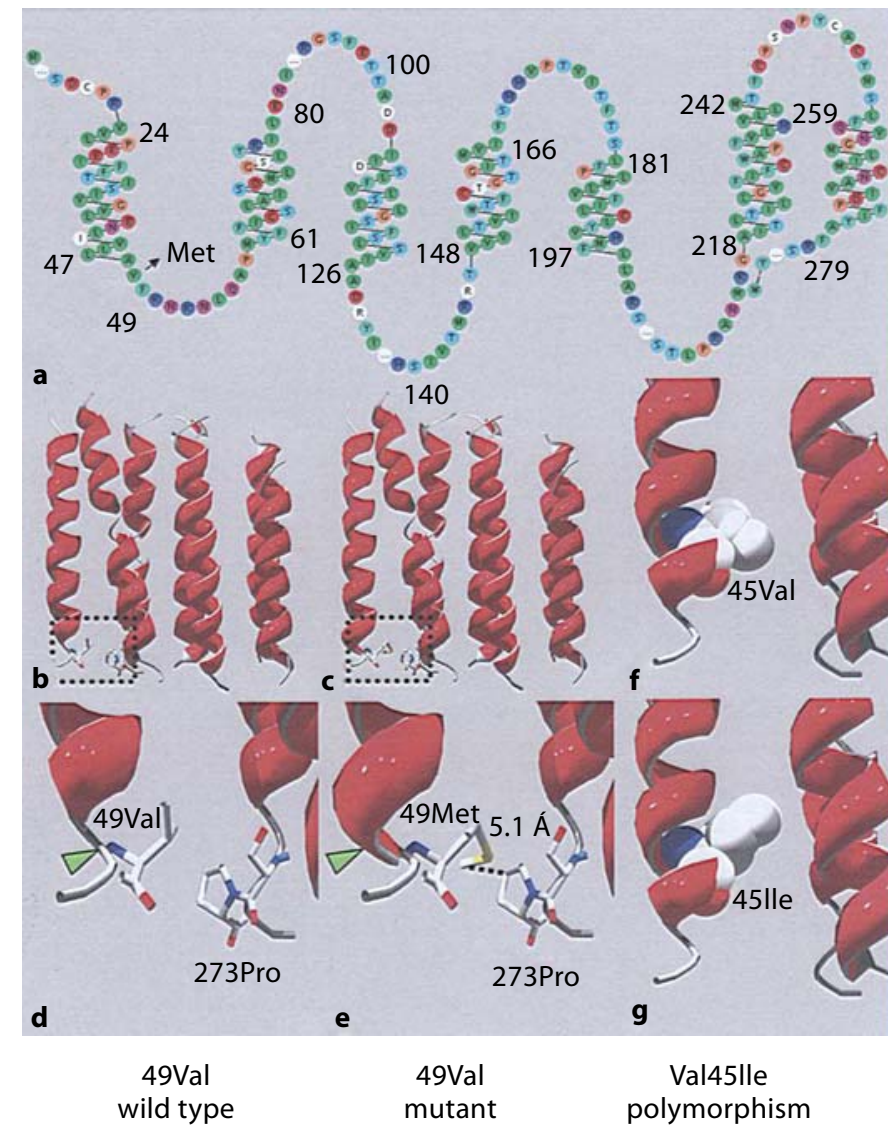

Fig. 2. a $2 \mathrm{D}$ snake diagram of the $\mathrm{MC} 2$ receptor taken from GCPRDB. The Val49Met mutation is located in junction zone between the first TMD and the first intracellular loop. Known mutations are depicted in white. $\mathbf{b}, \mathbf{c}$ No gross distortion of the seven TMDs can be seen in the presence the mutation (49Met). The dotted boxes are zoomed in the lower panel. $\mathbf{d}$, e Close inspection of the C-terminus of the first TMD reveals the alpha-helix of to be enlarged by two amino acids in the presence of the Val49Met mutation (arrow). Additionally, the methyl-groups of 49Met and 273Pro come into close contact thus enabling hydrophobic interaction. $\mathbf{f}, \mathbf{g}$ No change of the alpha-helix is seen in the presence of the Val45Ile mutation.

lular loop of the receptor. The 1-bp deletion c.137delT results in a shift of the open reading frame after Leu46 followed by a premature stop codon after 37 amino acids. It can be assumed that this markedly truncated protein will be functionless. Most of the mutations described so far are missense mutations. This heterozygous p.Leu46fs mutation adds to the small number of nonsense mutations and is the first frameshift mutation within the first transmembrane domain of the MC2R. The second mutation p.Val49Met results in an exchange of a hydrophobic nonpolar amino acid valine by the sulfur-containing hydrophobic non-polar amino acid methionine. The functional relevance of the second mutation can only be inferred from molecular modeling. The distortion of the C-terminus of the first TMD and of the first intracellular loop may result in a loss of signal transduction rather than a structural disruption or impairment of ligand binding on the extracellular surface. The adjacent naturally occurring mutation p.Ile44Met results in a near loss of signal transduction but shows virtually normal binding parameters [11]. On the other hand, the p.Val45Ile mutation, found as a heterozygous mutation in one FGD patient with a normal second allele, did not significantly alter the signal transduction pathway and was assumed to be a polymorphism [12]. This can be confirmed by molecular modeling in that the alpha-helix of TMD I is not changed with the Val45Ile polymorphism.

The different functional relevance of the p.Ile44Met and the p.Val45Ile mutations demonstrates that each amino acid must have its unique role for ACTH receptor function, and we assume that the Val49Met at the junction of the first transmembrane domain to the first intracellular loop will probably be a disease-causing mutation. Moreover, the valine 49 is highly conserved between different species (fig. 3), the mutation has not been found in 60 unrelated healthy control subjects and the mutation segregates with the disease in the family suggesting that this residue might have an important role for MC2R function.

In the past, poor correlation between gene defect and clinical phenotype was observed. Even in patients carrying identical $M C 2 R$ mutations, differences in phenotype exist [11]. Moreover, a poor correlation between severity of receptor dysfunction determined in vitro and the age of onset of the symptoms as well as disease severity and plasma cortisol levels was reported $[3,7,13]$. Some patients with FGD type 1 have been described to be unusually tall $[11,14]$. The measurements of human growth hormone and insulin-like growth factor (IGF-1) in these patients remained normal [3]. Tall stature and advanced bone age were described in patients with FGD, but not all the patients with the same $M C 2 R$ mutation presented with tall stature. It is suspected that the advanced bone age and growth may be due to high levels of ACTH and its action on MSH receptors in bone cartilage, as well as estradiol synthesis stimulation with a consecutive influence on bone tissue. Anabolic action of growth hormone without the catabolic cortisol influence could be another explanation $[15,16]$. Our patient presented with a normal growth rate slightly above the 50th percentile with an ab- 


\begin{tabular}{|lr|}
\hline & \\
HUMAN & MKHIINSYENINNTARNNSDCPRVVLPEEIFFTISIVGVLENLIVLLAVFKNKNLQAPMY \\
BOVIN & MKHILNLYENINSTARNNSDCPAVILPEEIFFTVSIVGVLENLMVLLAVAKNKSLQSPMY \\
PIG & MKHITDLYESVNSTMSNKSDCPPVVLPEEVFFISVIGVLENLIVLLAVIKNKNLSPMY \\
ELEMA & MKHIINPYENINNSARNNSDCPPVVLPEEIFFTISIVGVLENLIVLLAVIKNKNLQSPMY \\
SHEEP & MRHILNLYENINSTARNNSDCPAVILPEEIFFTVSIVGVLENMVLAVAKNKSQSPMY \\
MOUSE & MKHIINSYEHTNDTARNNSDCPDVVLPEEIFFTISVIGILENLIVLLAVIKNKNLSPMY \\
CAVPO & MKHIIHASGNVNGTARNNSDCPHVALPEEIFFIISITGVLENLIIILAVIKNKNLQFPMY \\
MESAU & MKHIITPYEHTNDTARNNSDCPDVVLEEIFFTISIIGVLENLIVLLAVVKKNLCPMY \\
CHICK & IPSLENITDFSLNITDCNQVVVPEEVFFTVAAGILENLLVLVAVIRNKNLHLPMY \\
BRARE & HTDCAEVQVPGQVFLVIAVASLSENLLVIVAVIKNKNLHSPMY \\
TETNI & MNATTVNRSDCPEVNVPIHIFFTIGFVSLAENLLVIVAIFWNRNLHSPMY \\
TAKRU & MNATTVNRSDCPEVNVPIHVFFTIGFVSLLENLLVIGAISWNRNLHSPMY \\
\end{tabular}

Fig. 3. Homology comparison of the first 60 amino acids of MC2R protein sequence from twelve different species (human: Homo sapiens AAI04171, bovine: Bos taurus P34974, pig: Sus scrofa Q8HYN8, elema: Elephans maximus ABG37017, ovine: Ovis aries Q9TU77, mouse: Mus musculus Q64326, cavpo: Cavia porcellus Q9Z1S9, mesau: Mesocricetus auratus P70115, chick: Gallus gallus NP_001026686, brare: Danio rerio AAO24743, tetni: Tetraodon nigroviridis AAQ55177, takru: Takifugu rubripes AAO65550). Amino acids which are different in comparison with the human sequence are highlighted in gray, conservative substitutions are indicated with bold letters. The amino acids L46 and V49 are indicated with an asterisk.

solute height within the midparental range. However, his bone age was found to be dissociated and retarded.

The incidence of FGD in the general population is not known. It is a rare disease and more than 50 cases have been reported so far [5]. However, the FGD incidence could be underestimated because some patients may be misdiagnosed as having just recurrent infections or seizures. A misinterpretation of these symptoms may be fatal for the patient as hypoglycemic shock followed by cerebral damage or death has repeatedly been reported in FGD families.

In our patient, skin hyperpigmentation as well as muscle weakness were present from birth. The prolonged jaundice points to the clinically relevant cortisol deficiency as it can be seen in patients with neonatal hypopituitarism $[17,18]$. It was proposed that cortisol can influence bile formation, and a reduction of bile flow has been observed in adrenalectomized rats [19]. In fact, cholestasis and neonatal hepatitis has been described as a leading symptom in isolated glucocorticoid deficiency [20].

Our patient presented with an elevated TSH concentration at the age of 3 months with normal levels of peripheral thyroid hormones. In order to prevent any hypothyroid episode in early infancy, we started treatment with a low dose of L-thyroxine. The reason for the TSH elevation remains uncertain, although within the first year of life the TRH-TSH axis can be activated which may result in high TSH levels despite peripheral euthyroidism. As thyroid ultrasound was normal in our patient, we stopped thyroxine treatment, and re-evaluation of thyroid function revealed normal results in a 1.5-year followup. This case is obviously different from the observation of Tiosano et al. who described a large consanguineous kindred with FGD and profound hypothyroidism, the latter being due to a novel point mutation in the thyrotropin receptor leading to TSH resistance [21]. In this family, the presence of hypothyroidism did not affect the timing, severity and manner of the isolated glucocorticoid deficiency.

The treatment of FGD consists of glucocorticoid substitution therapy, which helps re-establish normal metabolism as well as normal growth [15]. Typical oral hydrocortisone doses are $12-15 \mathrm{mg} / \mathrm{m}^{2} /$ day. Clinical signs of effective FGD treatment are: normal height and weight gain, reduction of the frequency of severe infections, and normal glucose concentration in blood. In our patient, we had to start with an initial dose of $30 \mathrm{mg} / \mathrm{m}^{2} /$ day, then lowered the dose to $15-20 \mathrm{mg} / \mathrm{m}^{2} /$ day. On this treatment, ACTH levels returned to normal, which is not always the case in FGD patients [22].

As in other glucocorticoid-treated patients, growth and development of the children should be carefully monitored, and the hydrocortisone dose needs to be appropriately increased in times of fever, stress and surgery. No mineralocorticoid treatment is required. Twenty fourhour ambulatory medical aid should be easily accessible to those patients in case of emergency. Frequent outpatient clinic visits are essential to establish and maintain 
the treatment with the lowest possible dose of steroids. We recommend to offer genetic counseling to the affected families.

\section{Methods}

Blood samples were taken from the family after obtaining written informed consent. Primer sequences and PCR conditions used for amplification of exon 2 of the $M C 2 R$ gene are available upon request. For sequencing, PCR products were purified with the QIAquick PCR Purification Kit (Qiagen, Hilden, Germany). The sequencing was performed with an ABI 3100 Genetic Analyzer (Applied Biosystems, Foster City, Calif., USA) using the Big Dye Terminator v 1.1 Cycle Sequencing kit (Applied
Biosystems). Base calling was done with the DNA Sequencing Analysis Software, version 3.7 (Applied Biosystems) and sequences were aligned and analyzed with the Sequence Navigator software, version 1.0.1 (Applied Biosystems). In 60 healthy control individuals, we sequenced nucleotides 1-271 (amino acid 1-90) and did not find sequence abnormalities at amino acid positions L46 and V49.

\section{Acknowledgments}

We thank Dana Landgraf for excellent technical assistance.

\section{References}

1 Shepard TH, Landing BH, Mason DG: Familial Addison's disease: case reports of two sisters with corticoid deficiency unassociated with hypoaldosteronism. Am J Dis Child 1959;97:154-162.

2 Weber A, Clark AJ: Mutations of the ACTH receptor gene are only one cause of familial glucocorticoid deficiency. Hum Mol Genet 1994;4:585-588.

3 Weber A, Toppari J, Harvey R, Klann RC, Shaw NJ, Ricker AT, Nanto-Salonen K, Bevan JS, Clark AJ: Adrenocorticotropin receptor gene mutations in familial glucocorticoid deficiency: relationships with clinical features in four families. J Clin Endocrinol Metab 1995;80:65-71.

4 Clark AJ, Weber A: Adrenocorticotropin insensitivity syndromes. Endocr Rev 1998;19: 828-843.

5 Clark AJ, Metherell LA, Naville D, Begeot M, Huebner A: Genetics of ACTH insensitivity syndromes. Ann Endocrinol (Paris) 2005;66: 247-249.

6 Metherell LA, Chan LF, Clark AJ: The genetics of ACTH resistance syndromes. Best Pract Res Clin Endocrinol Metab 2006;20: 547-560.

7 Metherell LA, Chapple JP, Cooray S, David A, Becker C, Ruschendorf F, Naville D, Begeot M, Khoo B, Nurnberg P, Huebner A, Cheetham ME, Clark AJ: Mutations in MRAP, encoding a new interacting partner of the ACTH receptor, cause familial glucocorticoid deficiency type 2. Nat Genet 2005; 37:166-170.

8 Genin E, Huebner A, Jaillard C, Faure A, Halaby G, Saka N, Clark AJ, Durand P, Begeot $\mathrm{M}$, Naville D: Linkage of one gene for familial glucocorticoid deficiency type 2 (FGD2) to chromosome $8 \mathrm{q}$ and further evidence of heterogeneity. Hum Genet 2002;111:428434.
9 Prusis P, Schiöth HB, Muceniece R, Herzyk P, Afshar M, Hubbard RE, Wikberg JE: Modeling of the three-dimensional structure of the human melanocortin 1 receptor using an automated method and docking of a rigid cycling melanocyte-stimulating hormone core peptide. J Mol Graph Model 1997;15:307317.

10 Skrabanek L, Campagne F, Weinstein $\mathrm{H}$ : Building protein diagrams on the web with the residue-based diagram editor RbDe. Nucleic Acids Res 2003;31:3856-3858.

11 Elias LL, Huebner A, Pullinger GD, Mirtella A, Clark AJ: Functional characterization of naturally occurring mutations of the human adrenocorticotropin receptor: poor correlation of phenotype and genotype. J Clin Endocrinol Metab 1999;84:2766-2770.

12 Naville D, Barjhoux L, Jaillard C, Faury D, Despert F, Esteva B, Durand P, Saez JM, Begeot M: Demonstration by transfection studies that mutations in the adrenocorticotropin receptor gene are one cause of the hereditary syndrome of glucocorticoid deficiency. J Clin Endocrinol Metab 1996;81: 1442-1448.

13 Naville D, Weber A, Genin E, Durand P, Clark AJ, Begeot M: Exclusion of the adrenocorticotropin (ACTH) receptor (MC2R) locus in some families with ACTH resistance but no mutations of the MC2R coding sequence (familial glucocorticoid deficiency type 2). J Clin Endocrinol Metab 1998;83: 3592-3596.

14 Huebner A, Elias LL, Clark AJ: ACTH resistance syndromes. J Pediatr Endocrinol Metab 1999;12(suppl 1):277-293.
15 Elias LL, Huebner A, Metherell LA, Canas A, Warne GL, Bitti ML, Cianfarani C, Clayton PL, Savage MO, Clark AJ: Tall stature in familial glucocorticoid deficiency. Clin Endocrinol (Oxf) 2000;53:423-430.

16 Imamine $\mathrm{H}$, Mizuno H, Sugiyama Y, Ohro Y, Sugiura T, Togari H: Possible relationship between elevated plasma ACTH and tall stature in familial glucocorticoid deficiency. Tohoku J Exp Med 2005;205:123-131.

17 Sheehan AG, Martin SR, Stephure D, Scott RB: Neonatal cholestasis, hypoglycemia, and congenital hypopituitarism. J Pediatr Gastroenterol Nutr 1992;14:426-430.

18 Choo-Kang LR, Sun CC, Counts DR: Cholestasis and hypoglycemia: manifestations of congenital anterior hypopituitarism. J Clin Endocrinol Metab 1996;81:2786-2789.

19 Leblanc A, Odievre M, Hadchouel M, Gendrel D, Chaussain JL, Rappaport R: Neonatal cholestasis and hypoglycemia: possible role of cortisol deficiency. J Pediatr 1981;99:577580.

20 Lacy DE, Nathavitharana KA, Tarlow MJ: Neonatal hepatitis and congenital insensitivity to adrenocorticotropin (ACTH). J Pediatr Gastroenterol Nutr 1993;17:438-440.

21 Tiosano D, Pannain S, Vassart G, Parma J, Gershoni-Baruch R, Mandel H, Lotan R, Zaharan Y, Pery M, Weiss RE, Refetoff S, Hochberg Z: The hypothyroidism in an inbred kindred with congenital thyroid hormone and glucocorticoid deficiency is due to a mutation producing a truncated thyrotropin receptor. Thyroid 1999;9:887-894.

22 Clark AJL, Metherell LA, Cheetham ME, Huebner A: Inherited ACTH insensitivity illuminates the mechanisms of ACTH action. Trends Endocrinol Metab 2006;16:451-457. 